\title{
Regioselectivity in the hetero-Diels-Alder reactions of styrenes with 2-aza-1,3-butadiene: a DFT study
}

\author{
SAFA ALI-ASGARI*10, JAFAR IZADI NIA and SAMIRA ZALI \\ Department of Chemistry, Shahrood Branch, Islamic Azad University, Shahrood, Iran \\ E-mail: safa1308@yahoo.com; s_aliasgari@iau-shahrood.ac.ir
}

MS received 28 February 2017; revised 14 May 2017; accepted 19 May 2017

\begin{abstract}
In this work, regioselectivity was investigated in the hetero-Diels-Alder reactions of styrenes (without substituent and with para-substituted groups) with 2-aza-1,3-butadiene from thermodynamic (Hammett study), electronic (HSAB criterion) and kinetic viewpoints. Furthermore, the effect of the presence of catalyst was inspected by the NBO analysis in addition to kinetic studies. The calculations were performed by the Gaussian 09 program at the B3LYP/6-311++G** level of theory in the gas phase. Thermodynamically, the stability difference between the two regioisomeric products is not significant, especially, in the reactions of styrenes with electron-releasing substituents. Kinetically, the obtained regioselectivity is in favor of formation of 4-regioisomers, especially, in the presence of $\mathrm{BF}_{3}$ catalyst (in agreement with the NBO results). On the basis of the HSAB criterion, 5-regioisomers have preference, only in the reactions of styrenes with the strong electron-withdrawing substituents.
\end{abstract}

Keywords. Regioselectivity; hetero-Diels-Alder reaction; styrene; 2-aza-1,3-butadiene; HSAB; NBO.

\section{Introduction}

The Diels-Alder (DA) reaction is a very attractive tool in organic synthesis, especially in the areas of synthesis of hexagonal heterocycles and natural products. ${ }^{1,2}$ This reaction is classified into two categories which are carbo-DA (CDA) and hetero-DA (HDA). Additionally, the HDA reaction can be divided into oxa-DA (DA with carbonyl compounds) and imino- or azaDA (DA with imine compounds). The DA reaction is accomplished in the presence of a broad range of Lewis acid catalysts such as $\mathrm{BF}_{3}, \mathrm{ZnCl}_{2}, \mathrm{CuCl}$ and $\mathrm{AlCl}_{3}$. It is worth mentioning that the reaction yield is normally increased by putting the electron-withdrawing substituents on the dienophile or the electron-releasing substituents on diene. By varying the nature of the diene or dienophile, many different carbocyclic or heterocyclic structures can be built up. ${ }^{3}$ A selected number of [4+2] cycloadditions of simple 2-aza-1,3butadienes have been described until now. On the other hand, Hammett parameters were developed, and initially employed, to describe the reactivity at an atom directly

\footnotetext{
*For correspondence
}

bonded to an aromatic ring, meta- or para- to a substituent group. ${ }^{4,5}$

Despite the valuable results obtained in experimental studies, the reaction mechanism, substituent effects and the molecular orbital viewpoint (for justifying the regioselectivity and stereoslectivity) cannot be appropriately and systematically explained by using these studies. In this study, regioselectivity was investigated in aza-DA reactions of styrenes (without substituent and with para-substituted electron-withdrawing and electron-releasing groups) with 2-aza-1,3-butadiene (Figure 1). Each of these reactions produces two regioisomeric products: two unsubstituted or parasubstituted 4-phenyl and 5-phenyl derivatives of aza-1cyclohexene. The effect of presence of the catalyst was also another case of special attention.

\section{Computational details}

The geometries of all the reactants and transition states (in the absence and the presence of $\mathrm{BF}_{3}$ catalyst) and products were fully optimized by using the quantum chemical calculations of density functional theory (DFT) with the B3LYP method and $6-311++\mathrm{G}^{* *}$ basis set in the gas phase. The 


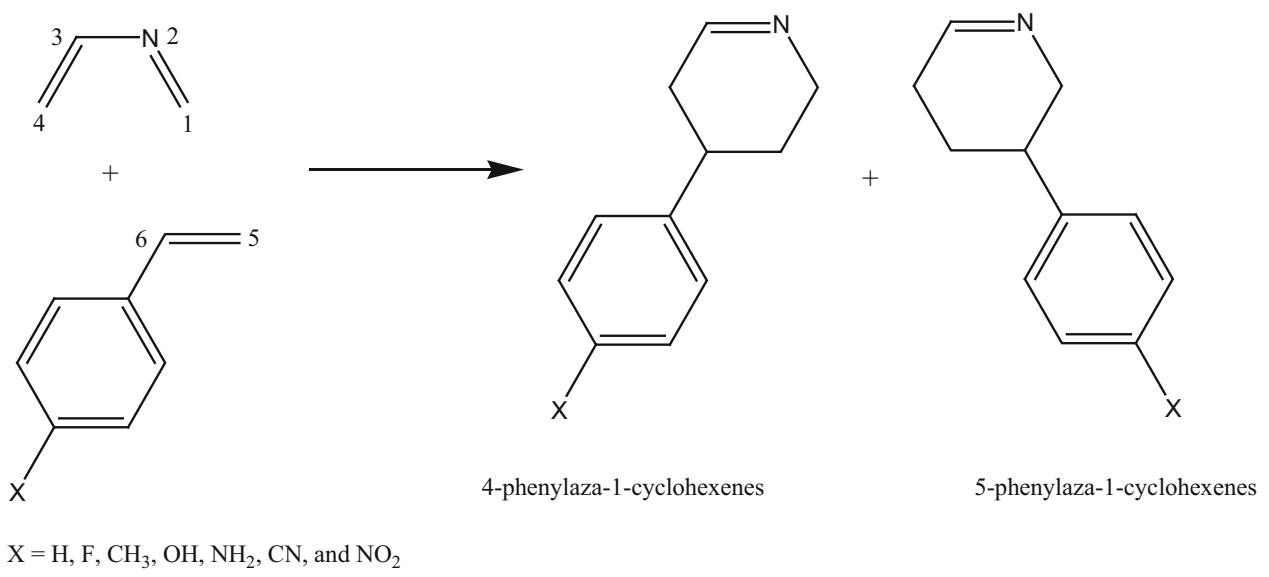

Figure 1. The DA reaction of styrenes with 2-aza-1,3-butadiene that leads to two regioisomers.

Table 1. The $\Delta \mathrm{H}^{\circ}(\mathrm{kcal} / \mathrm{mol})$ and $\mathrm{K}_{\mathrm{eq}}$ values of the DA reactions of styrenes with 2-aza-1,3-butadiene in two paths leading to two regioisomers.

\begin{tabular}{|c|c|c|c|c|}
\hline \multirow[t]{2}{*}{$\mathrm{X}$} & \multicolumn{2}{|c|}{ 4-phenylaza-1-cyclohexenes } & \multicolumn{2}{|c|}{ 5-phenylaza-1-cyclohexenes } \\
\hline & $\Delta \mathrm{H}^{\circ}$ & $\mathrm{K}_{\mathrm{eq}}$ & $\Delta \mathrm{H}^{\circ}$ & $\mathrm{K}_{\mathrm{eq}}$ \\
\hline $\mathrm{H}$ & -33.59 & $1.28 \times 10^{14}$ & -33.66 & $1.33 \times 10^{14}$ \\
\hline $\mathrm{F}$ & -33.56 & $1.21 \times 10^{14}$ & -33.68 & $1.46 \times 10^{14}$ \\
\hline $\mathrm{CH}_{3}$ & -33.50 & $6.03 \times 10^{13}$ & -33.56 & $7.55 \times 10^{13}$ \\
\hline $\mathrm{OH}$ & -33.27 & $8.73 \times 10^{13}$ & -33.40 & $1.06 \times 10^{14}$ \\
\hline $\mathrm{NH}_{2}$ & -32.98 & $7.04 \times 10^{13}$ & -33.02 & $8.32 \times 10^{13}$ \\
\hline $\mathrm{CN}$ & -33.60 & $1.43 \times 10^{14}$ & -33.81 & $2.35 \times 10^{14}$ \\
\hline $\mathrm{NO}_{2}$ & -39.26 & $9.78 \times 10^{18}$ & -39.49 & $1.64 \times 10^{19}$ \\
\hline
\end{tabular}

B3LYP is extremely popular, because it gives very good results and, therefore, is often the method of choice for reaction chemistry calculations. The B3LYP is an approximate hybrid density functional theory which combines Becke's 3-parameter density functional formalism with the Lee-YangParr correlation functional. ${ }^{6-9}$ The triple- $\zeta$ basis set adds three sizes of $s$ and $p$ functions to atoms, and adds a $d$ function to each heavy atom and a $p$ function to the hydrogen atom, as well as diffuse functions on heavy atoms and hydrogen atoms. Geometry optimizations were performed without any symmetry constraint. The nature of stationary species was confirmed by the computation of harmonic frequencies and using the same level of theory. For each minimum state (related to a reactant or a product) and for each transition state, only real frequency values and only a single imaginary frequency were accepted, respectively. Normal modes corresponding to the imaginary frequencies are related to vibrations of the new developing bonds in transition state structures. Stabilities of restricted wave functions towards unrestricted alternatives for each reactant were verified using STABLE keyword and instability was not observed at all. ${ }^{10}$ In the calculations of Fukui functions, the cationic and anionic systems were kept at the optimized geometries of their neutral counterparts. It should be mentioned that Fukui functions resulted from various population schemes may lead to negative values while Hirshfeld's population scheme always provides positive values. ${ }^{11,12}$ Therefore, here, the Fukui functions were obtained based on Hirshfeld populations. A reaction model was employed in which $\mathrm{BF}_{3}$ as a Lewis acid catalyst was directly interacting with the nitrogen lone pair of 2-aza-1,3butadiene. Also, the NBO analysis was accomplished for each optimized transition state in the presence of $\mathrm{BF}_{3}$ catalyst at the aforementioned level of theory. All calculations were performed by the Gaussian 09 program. ${ }^{13}$

\section{Results and Discussion}

\subsection{The Hammett study}

Two thermodynamic data $\left(\Delta \mathrm{H}^{\circ}\right.$ and $\left.\mathrm{K}_{\mathrm{eq}}\right)$ are presented in Table 1 for the DA reactions of styrenes (unsubstituted $(\mathrm{X}=\mathrm{H})$ and with a substituent group in para position of the styrene ring $\left(\mathrm{X}=\mathrm{F}, \mathrm{CH}_{3}, \mathrm{OH}, \mathrm{NH}_{2}, \mathrm{CN}\right.$, and $\left.\mathrm{NO}_{2}\right)$ ) with 2-aza-1,3-butadiene in two paths leading to two regioisomers. Moreover, Figure 2 represents changes of $\log \left(\mathrm{K} / \mathrm{K}_{0}\right)$ against the sigma values for the above men- 


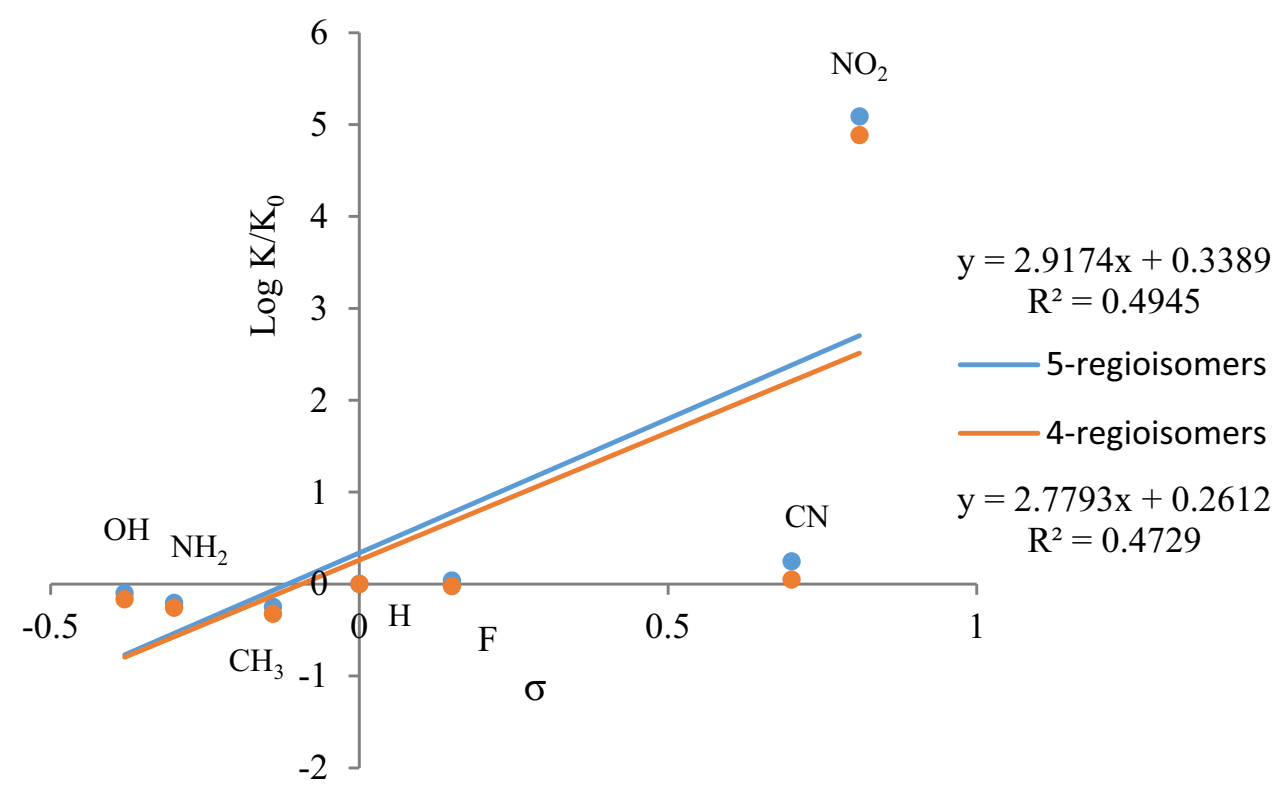

Figure 2. Hammett diagram for formation of 4- and 5-phenylaza-1-cyclohexenes (the straight line obtained as a linear fit to the data should only be taken as a guide to the eye).

tioned substituent groups in para position of the styrene ring. ${ }^{5}$

The results indicate that for both regioisomers, as expected, the electron-withdrawing groups increase equilibrium constant of the exothermic and complete DA reactions between each of the substituted styrenes and 2-aza-1,3-butadiene. Also, the sensitivity of the reaction to substituent effects is almost identical for the formation of both 4- and 5-regioisomers and therefore, from the thermodynamic point of view, it cannot be considered as a regioselective reaction, especially for styrenes without the strong electron-withdrawing substituents.

\subsection{The HSAB criterion}

The qualitative frontier molecular orbital theory, as first expressed by Fukui, ${ }^{14}$ continues to be utilized extensively by organic chemists to predict cycloadducts regiochemistry. If one considers the frontier orbital relative energies for diene and dienophile systems, the DA reactions can be divided into two limiting categories: (1) the normal electron demand (NED) DA reaction, $\mathrm{HOMO}_{\text {diene }}-\mathrm{LUMO}_{\text {dienophile }}$ controlled, and (2) the inverse electron demand (IED) type, in which the energy gap between $\mathrm{HOMO}_{\text {dienophile }}$ and $\mathrm{LUMO}_{\text {diene }}$ governs the reaction rate. ${ }^{15}$ Furthermore, in the cycloaddition reactions, regioselectivity has been described in terms of a local hard and soft acid and base (HSAB) principle, which is also recognized as Gazquez-Mendez rule: the less the softness difference of two interacting atoms, the more favored is interaction between those two atoms. ${ }^{16-18}$ Hence, here, regioselectivity of DA reactions of styrene and para-substituted styrenes $\left(\mathrm{X}=\mathrm{H}, \mathrm{F}, \mathrm{CH}_{3}\right.$, $\mathrm{OH}, \mathrm{NH}_{2}, \mathrm{CN}$, and $\mathrm{NO}_{2}$ ) as dienophiles with 2-aza1,3-butadiene as diene was investigated by the HSAB criterion.

As mentioned earlier, each reaction produces two regioisomers (a 4-phenyl derivative (A) and a 5-phenyl derivative (B) of aza-1-cyclohexene). The calculated values of chemical potential $(\mu)$, softness $(S)$, Fukui functions $\left(f^{+} / f^{-}\right)$, and softness difference $\left(\Delta S_{\mathrm{A}}\right.$ and $\Delta S_{\mathrm{B}}$ ), and also, NED/IED character related to each of these reactions are tabulated in Table 2 .

Electronic chemical potential and softness are global descriptors and defined as follows:

$$
\begin{aligned}
\mu & =\frac{1}{2}\left(\varepsilon_{\text {HOMO }}+\varepsilon_{\text {LUMO }}\right) \\
\frac{1}{\mathrm{~S}} & =\left(\varepsilon_{\text {LUMO }}-\varepsilon_{\text {HOMO }}\right)
\end{aligned}
$$

where, $\varepsilon_{\text {Номо }}$ and $\varepsilon_{\text {LUMO }}$ symbolize the highest occupied molecular orbital energy and the lowest unoccupied molecular orbital energy, respectively. ${ }^{19,20}$

Local descriptors such as Fukui functions and local softness define the reactivity and selectivity of an atomic site in a molecule. Fukui functions of any atom, $\mathrm{k}$, in a molecule with $\mathrm{N}$ electrons are calculated by the following condensed equations, corresponding to the type of electron transfer:

$$
f_{\mathrm{k}}^{+}=\left[\rho_{\mathrm{k}}(\mathrm{N}+1)-\rho_{\mathrm{k}}(\mathrm{N})\right],
$$
for atom $\mathrm{k}$ of electrophilic species 
Table 2. The values of chemical potential, $\mu$ (a.u.), softness, $S$ (a.u. ${ }^{-1}$ ), Fukui functions $\left(f^{+} / f^{-}\right)$, and softness difference $(\Delta S)$, and NED/IED character related to the regioselective DA reactions of styrenes with 2-aza-1,3-butadiene.

\begin{tabular}{|c|c|c|c|c|c|c|c|c|c|c|c|}
\hline \multirow[t]{2}{*}{$\mathrm{X}$} & \multicolumn{4}{|c|}{ Diene (2-aza-1,3-butadiene) } & \multicolumn{4}{|c|}{ Dienophile (styrenes) } & \multirow[t]{2}{*}{$\Delta S_{\mathrm{A}}$} & \multirow[t]{2}{*}{$\Delta S_{\mathrm{B}}$} & \multirow[t]{2}{*}{ NED/IED } \\
\hline & $\mu$ & $S$ & $f_{1}^{+} / f_{1}^{-}$ & $f_{4}^{+} / f_{4}^{-}$ & $\mu$ & $S$ & $f_{5}^{+} / f_{5}^{-}$ & $f_{6}^{+} / f_{6}^{-}$ & & & \\
\hline $\mathrm{H}$ & -0.168 & 5.13 & 0.214 & 0.164 & -0.142 & 5.41 & 0.158 & 0.080 & 0.23 & 0.44 & IED \\
\hline F & -0.168 & 5.13 & 0.214 & 0.164 & -0.145 & 5.43 & 0.155 & 0.076 & 0.25 & 0.47 & IED \\
\hline $\mathrm{CH}_{3}$ & -0.168 & 5.13 & 0.214 & 0.164 & -0.136 & 5.50 & 0.148 & 0.069 & 0.29 & 0.52 & IED \\
\hline $\mathrm{OH}$ & -0.168 & 5.13 & 0.214 & 0.164 & -0.131 & 5.65 & 0.141 & 0.061 & 0.34 & 0.57 & IED \\
\hline $\mathrm{NH}_{2}$ & -0.168 & 5.13 & 0.214 & 0.164 & -0.119 & 5.97 & 0.127 & 0.048 & 0.42 & 0.67 & IED \\
\hline $\mathrm{CN}$ & -0.168 & 5.13 & 0.167 & 0.233 & -0.174 & 6.13 & 0.101 & 0.046 & 0.89 & 0.66 & NED \\
\hline $\mathrm{NO}_{2}$ & -0.168 & 5.13 & 0.167 & 0.233 & -0.170 & 5.85 & 0.126 & 0.057 & 0.76 & 0.48 & NED \\
\hline
\end{tabular}

$f_{\mathrm{k}}^{-}=\left[\rho_{\mathrm{k}}(\mathrm{N})-\rho_{\mathrm{k}}(\mathrm{N}-1)\right]$,

for atom $\mathrm{k}$ of nucleophilic species

(3b)

where, $\rho_{\mathrm{k}}(\mathrm{N}), \rho_{\mathrm{k}}(\mathrm{N}-1)$, and $\rho_{\mathrm{k}}(\mathrm{N}+1)$ are the gross electronic population of atom $\mathrm{k}$ in neutral, cationic and anionic systems, respectively. ${ }^{21,22}$

The local softness, $s_{\mathrm{k}}^{\alpha}$, can be readily calculated as follows:

$s_{\mathrm{k}}^{\alpha}=\mathrm{S} f_{\mathrm{k}}^{\alpha}$

Here, + and - values for $\alpha$ refer to electrophilic and nucleophilic species, respectively. ${ }^{23}$

The $\Delta S$ values for formation of each of the two regioisomers have been computed by using the following formulas at both IED and NED reaction modes (see Figure 1 for numbering of atoms).

$$
\begin{aligned}
& \Delta S_{\mathrm{A}}^{\mathrm{IED}}=\left(s_{5}^{-}-s_{1}^{+}\right)^{2}+\left(s_{6}^{-}-s_{4}^{+}\right)^{2} \\
& \Delta S_{\mathrm{B}}^{\mathrm{IED}}=\left(s_{5}^{-}-s_{4}^{+}\right)^{2}+\left(s_{6}^{-}-s_{1}^{+}\right)^{2} \\
& \Delta S_{\mathrm{A}}^{\mathrm{NED}}=\left(s_{1}^{-}-s_{5}^{+}\right)^{2}+\left(s_{4}^{-}-s_{6}^{+}\right)^{2} \\
& \Delta S_{\mathrm{B}}^{\mathrm{NED}}=\left(s_{4}^{-}-s_{5}^{+}\right)^{2}+\left(s_{1}^{-}-s_{6}^{+}\right)^{2}
\end{aligned}
$$

Based on the smaller value of $\Delta S$ for preferred pathway, the major product of the IED reactions is 4-regioisomers (A) while in the two NED reactions, 5regioisomers (B) are preferred.

As can be seen, most of the investigated reactions proceed via the IED mode, that is, HOMO from dienophile (styrenes) and LUMO from diene (2-aza1,3-butadiene). This indicates that nitrogen heteroatom incorporation in diene skeleton leads to electron deficiency and consequently, diminishing the diene LUMO level. Reactions between 2-aza-1,3-butadiene and para$\mathrm{CN}$-styrene or para- $\mathrm{NO}_{2}$-styrene (styrenes with the strong electron-withdrawing substituents) have the NED character. In fact, on the basis of the resonance theory,

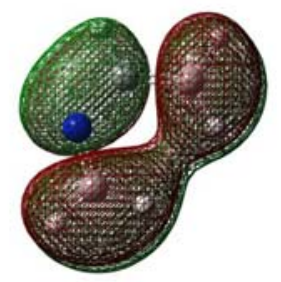

LUMO of 2-aza-1,3-butadiene
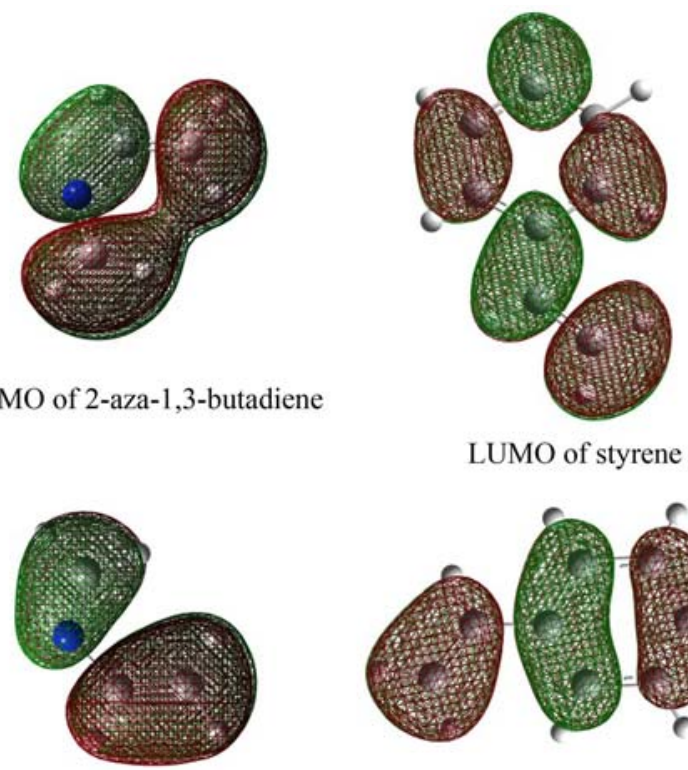

HOMO of 2-aza-1,3-butadiene

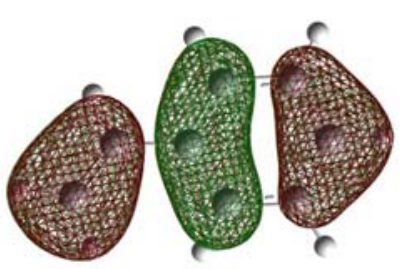

HOMO of styrene

Figure 3. The HOMO and LUMO orbitals of 2-aza-1,3-butadiene and styrene.

$\mathrm{C}-1$ is the positive end of the diene and in the IED reactions (containing styrenes without the strong electronwithdrawing substituents), C-5 bears negative charge; therefore, 4-regioisomers prevail in these reactions. On the other hand, 5-regioisomers prevail in the NED reactions (containing styrenes with the strong electronwithdrawing substituents) due to negative charge on C-6. Figure 3 shows the HOMO and LUMO orbitals of 2-aza-1,3-butadiene and styrene molecules.

3.3a The effect of the catalyst - kinetic study: Activation energies and rate constants of the DA reactions of styrenes with 2-aza-1,3-butadiene in the two paths leading to two regioisomers and in the absence and presence of $\mathrm{BF}_{3}$ Lewis acid catalyst are presented in Table 3. 
Table 3. The activation energy, $E_{a}(\mathrm{kcal} / \mathrm{mol})$, and rate constant, $k$ (L/mol.s), values of the DA reactions of styrenes with 2 -aza-1,3-butadiene in the two paths leading to two regioisomers, in the absence and presence of $\mathrm{BF}_{3}$ catalyst.

\begin{tabular}{|c|c|c|c|c|c|c|c|c|}
\hline \multirow[t]{3}{*}{ X } & \multicolumn{4}{|c|}{ 4-phenylaza-1-cyclohexenes } & \multicolumn{4}{|c|}{ 5-phenylaza-1-cyclohexenes } \\
\hline & \multicolumn{2}{|c|}{ Absence of catalyst } & \multicolumn{2}{|c|}{ Presence of catalyst } & \multicolumn{2}{|c|}{ Absence of catalyst } & \multicolumn{2}{|c|}{ Presence of catalyst } \\
\hline & $E_{a}$ & $k$ & $E_{a}$ & $k$ & $E_{a}$ & $k$ & $E_{a}$ & $k$ \\
\hline $\mathrm{H}$ & 17.46 & $2.29 \times 10^{-11}$ & 9.42 & $8.06 \times 1($ & 18.12 & $6.92 \times 10^{-12}$ & 14.11 & $2.24 \times 10^{-9}$ \\
\hline $\mathrm{F}$ & 17.77 & $1.47 \times 10^{-11}$ & 9.98 & $3.05 \times 10^{-6}$ & 18.48 & $3.56 \times 10^{-12}$ & 14.82 & $6.79 \times 10^{-10}$ \\
\hline $\mathrm{CH}_{3}$ & 17.44 & $2.84 \times 10^{-11}$ & 8.64 & $2.12 \times 10^{-5}$ & 18.34 & $2.33 \times 10^{-12}$ & 13.99 & $2.13 \times 10^{-9}$ \\
\hline $\mathrm{OH}$ & 17.45 & $3.01 \times 10^{-11}$ & 8.05 & $8.41 \times 10^{-5}$ & 18.61 & $3.13 \times 10^{-12}$ & 14.13 & $2.46 \times 10^{-9}$ \\
\hline $\mathrm{NH}_{2}$ & 17.02 & $9.10 \times 10^{-11}$ & 5.89 & $8.92 \times 10^{-3}$ & 18.73 & $3.22 \times 10^{-12}$ & 13.79 & $2.13 \times 10^{-9}$ \\
\hline $\mathrm{CN}$ & 17.58 & $1.64 \times 10^{-11}$ & 12.50 & $2.98 \times 10^{-8}$ & 17.65 & $1.19 \times 10^{-12}$ & 15.54 & $1.53 \times 10^{-10}$ \\
\hline $\mathrm{NO}_{2}$ & 11.85 & $1.29 \times 10^{-6}$ & 6.90 & $2.49 \times 10^{-3}$ & 11.69 & $1.59 \times 10^{-6}$ & 10.10 & $8.57 \times 10^{-6}$ \\
\hline
\end{tabular}

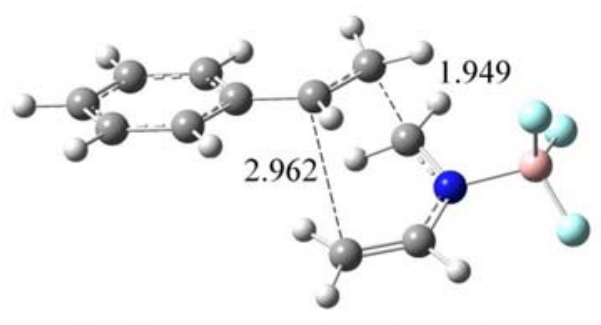

TS leading to 4-phenylaza-1-cyclohexene regioisomer in the presence of $\mathrm{BF}_{3}$ catalyst

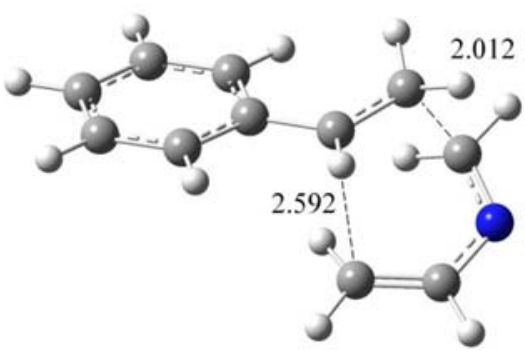

TS leading to 4-phenylaza-1-cyclohexene regioisomer in the absence of $\mathrm{BF}_{3}$ catalyst

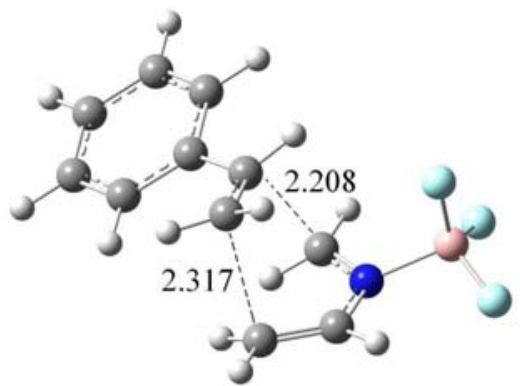

TS leading to 5-phenylaza-1-cyclohexene regioisomer in the presence of $\mathrm{BF}_{3}$ catalyst

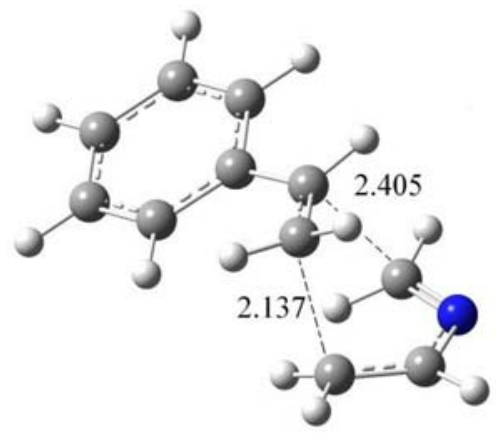

TS leading to 5-phenylaza-1-cyclohexene regioisomer in the absence of $\mathrm{BF}_{3}$ catalyst

Figure 4. The four TS structures of the reaction of styrene with 2-aza-1,3-butadiene in two paths leading to two regioisomers and in the absence and presence of $\mathrm{BF}_{3}$ catalyst (the values are in terms of $\AA$ ).

The comparison between the uncoordinated and the $\mathrm{BF}_{3}$-coordinated DA reactions of styrenes with 2-aza1,3-butadiene reveals that a discernible increase in the reaction rate is resulted by the presence of catalyst, especially for the formation of 4-regioisomers which can be associated with the more polar character of the cycloaddition in the IED reactions. Therefore, the presence of $\mathrm{BF}_{3}$ catalyst leads to increase in regioselectivity in favor of the formation of 4-regioisomers, especially for styrenes with the strong electron-releasing substituents $\left(\mathrm{NH}_{2}\right.$ and $\left.\mathrm{OH}\right)$.

Also, asynchronicity is in harmony with the above mentioned regioselectivity. In fact, with respect to the Houk rule, ${ }^{24}$ asynchronicity (based on the difference between the lengths of the two developing $\sigma$ bonds at the TSs) demonstrates that 4-regioisomers are preferred and this preference increases because of $\mathrm{BF}_{3}$ coordination. Figure 4, for instance, represents four TS structures of 
Table 4. The resonance energy values $(\mathrm{kcal} / \mathrm{mol})$ resulting from the delocalization $\mathrm{LP}(\mathrm{N}) \rightarrow \mathrm{LP}^{*}(\mathrm{~B})$ into the TSs of the DA reactions of styrenes with 2-aza-1,3-butadiene in two paths leading to two regioisomers in the presence of $\mathrm{BF}_{3}$ catalyst.

\begin{tabular}{lcc}
\hline $\mathrm{X}$ & 4-phenylaza-1-cyclohexenes & 5-phenylaza-1-cyclohexenes \\
\hline $\mathrm{H}$ & 324.47 & 300.01 \\
$\mathrm{~F}$ & 323.86 & 298.41 \\
$\mathrm{CH}_{3}$ & 327.36 & 301.14 \\
$\mathrm{CN}$ & 315.22 & 293.27 \\
$\mathrm{NO}_{2}$ & 311.34 & 291.43 \\
\hline
\end{tabular}

the reaction of styrene with 2-aza-1,3-butadiene for the formation of both 4- and 5-regioisomers in the absence and presence of $\mathrm{BF}_{3}$ catalyst, and also the lengths of two developing $\sigma$ bonds in each TS. As can be seen, the asynchronicity for the formation of 4-regioisomer in the absence of catalyst $(2.592-2.012=0.580)$ is greater than that of 5-regioisomer $(2.405-2.137=0.268)$ and even the difference between the two asynchronicities becomes more evident in the presence of catalyst $((2.962-1.949=1.013)-(2.317-2.208=0.109)>$ $0.580-0.268)$.

3.3b The effect of the catalyst - NBO study: Delocalization of electron density from a filled (bonding or lone pair) Lewis-type NBO to an empty (antibonding or Rydberg) non-Lewis NBO leads to a loss of occupancy. For each delocalization from a donor $\mathrm{NBO}(i)$ to an acceptor $\operatorname{NBO}(j)$, the resonance energy $\left(E_{2}\right)$ is measured by the following equation:

$E_{2}=\Delta E_{i j}=q_{i}\left[F_{(i, j)}^{2} /\left(\varepsilon_{i}-\varepsilon_{j}\right)\right]$

where, $q_{i}$ is the occupancy of donor orbital, $\varepsilon_{i}$ and $\varepsilon_{j}$ symbolize the diagonal elements (orbital energies), and $F_{(i, j)}$ represents the off-diagonal NBO Fock matrix elements. ${ }^{25}$

The resonance energy value resulting from the delocalization of lone pair of nitrogen atom, $\mathrm{LP}(\mathrm{N})$, to the vacant orbital of boron atom, $\mathrm{LP}^{*}(\mathrm{~B})$, of the catalyst $\mathrm{BF}_{3}$ into the exo transition states leading to 4-phenylaza1-cyclohexenes and 5-phenylaza-1-cyclohexenes is the most important stabilizing factor in these Lewis acidLewis base complexes, as presented in Table 4. It should be noted that the aforementioned delocalization is not observed in the TS structures towards para-hydroxy or para-amino substituted products because of a very strong interaction between diene and catalyst, so that, probably, a localized bond has been formed.

The larger resonance energy values for the TS structures towards 4-phenylaza-1-cyclohexenes demonstrate the stronger interactions in their corresponding complexes and consequently greater stability of these complexes. This is in good harmony with the kinetic results and then, again, the regioselectivity in favor of formation of 4-regioisomers is confirmed (especially more evident for styrenes without the strong electron-withdrawing substituents).

\section{Conclusions}

In the reactions of styrenes with the electron-releasing substituents, two regioisomeric products have very similar stabilities. Therefore, the hetero-Diels-Alder reactions of styrenes with 2-aza-1,3-butadiene are not very regioselective from the thermodynamic viewpoint.

On the basis of the HSAB criterion, most of the investigated DA reactions proceed via the IED mode and the major product of these reactions is 4-regioisomer while in the NED reactions (containing styrenes with the strong electron-withdrawing substituents), the major product is 5-regioisomer.

Kinetically, the regioselectivity is totally in favor of formation of 4-regioisomers. The presence of $\mathrm{BF}_{3}$ catalyst leads to increase in regioselectivity, especially for styrenes with the strong electron-releasing substituents. Also, asynchronicity (based on the Houk rule) demonstrates that 4-phenylaza-1-cyclohexenes are preferred and this preference increases because of $\mathrm{BF}_{3}$ coordination. Based on the NBO study on the TS structures of the considered reactions in the presence of $\mathrm{BF}_{3}$ catalyst, which is also in good harmony with the kinetic results, the obtained regioselectivity is in favor of the formation of 4-phenylaza-1-cyclohexenes, especially for styrenes without strong electron-withdrawing substituents.

\section{Supplementary Information (SI)}

Table $\mathrm{S} 1$ gives the energetics, containing $\Delta \mathrm{G}^{\circ}$ and $\Delta \mathrm{G}^{\ddagger}$ of all the studied reactions. The optimized structures of 
2-aza-1,3-butadiene (in the absence and presence of $\mathrm{BF}_{3}$ catalyst), para-substituted styrenes and para-substituted 4- and 5-phenylaza-1-cyclohexene products are shown in Figures S1-S3. Also, all the optimized TS structures of the DA reactions of para-substituted styrenes and 2-aza-1,3-butadiene in the absence and presence of $\mathrm{BF}_{3}$ catalyst are shown in Figures S4-S7. Supplementary Information is available at www. ias.ac.in/chemsci.

\section{References}

1. Carruthers W 1990 In Cycloaddition Reactions in Organic Synthesis (Oxford: Pergamon)

2. Friguelli F and Taticchi A 2002 In The Diels-Alder Reaction (England: John Wiley)

3. Houk K N, González J and Li Y 1995 Pericyclic Reaction Transition States: Passions and Punctilios, 1935-1995 Acc. Chem. Res. 2881

4. Hammett L P 1937 The Effect of Structure upon the Reactions of Organic Compounds Benzene Derivatives. J. Am. Chem. Soc. 5996

5. Carey F A and Sundberg R J 2007 In Advanced organic chemistry 5th edn. (New York: Springer) (and also the previous edition)

6. Lee C, Yang W and Parr R G 1988 Development of the Colle-Salvetti correlation-energy formula into a functional of the electron density Phys. Rev. B 37785

7. Stephens P J, Devlin F J, Chabalowski C F and Frisch M J 1994 Ab Initio Calculation of Vibrational Absorption and Circular Dichroism Spectra Using Density Functional Force Fields J. Phys. Chem. 9811623

8. Kim K and Jordan K D 1994 Comparison of Density Functional and MP2 Calculations on the Water Monomer and Dimer J. Phys. Chem. 9810089

9. Burke K, Perdew J P and Wang Y 1998 In Electronic Density Functional Theory: Recent Progress and New Directions J F Dobson, G Vignale and M P Das (Eds.) (New York: Plenum)

10. Head-Gordon M and Pople J A 1988 A Method for Two-Electron Gaussian Integral and Integral Derivative Evaluation Using Recurrence Relations J. Chem. Phys. 895777

11. Padmanabhan J, Parthasarathi R, Sarkar U, Subramanian V and Chattaraj P K 2004 Effect of solvation on the condensed Fukui function and the generalized philicity index Chem. Phys. Lett. 383122
12. Roy R K, Pal S and Hirao K 1999 On non-negativity of Fukui function indices J. Chem. Phys. 1108236

13. Frisch M J et al., 2009 Gaussian 09 Revision-A.02 SMP (Wallingford CT: Gaussian Inc.)

14. Fukui K 1981 The path of chemical reactions - the IRC approach Acc. Chem. Res. 14363

15. Domingo L R and Andres J 2003 Enhancing Reactivity of Carbonyl Compounds via Hydrogen-Bond Formation. A DFT Study of the Hetero-Diels-Alder Reaction Between Butadiene Derivative and Acetone in Chloroform J. Org. Chem. 688662

16. Gazquez J L and Mendez F 1994 The Hard and Soft Acids and Bases Principle: An Atoms in Molecules Viewpoint. J. Phys. Chem. 984591

17. Chandra A K and Nguyen M 2002 Use of Local Softness for the Interpretation of Reaction Mechanisms Int. J. Mol. Sci. 3310

18. Herrera R, Nagarajan A, Morales M A, Méndez F, Jiménez-Vázquez H A, Gerardo Zepeda L and Tamariz J 2001 Regio- and Stereoselectivity of Captodative Olefins in 1,3-Dipolar Cycloadditions. A DFT/HSAB Theory Rationale for the Observed Regiochemistry of Nitrones J. Org. Chem. 661252

19. Chattaraj P K, Sarkar U and Roy D R 2006 Electrophilicity Index Chem. Rev. 1062065

20. Koopmans T 1934 Über die Zuordnung von Wellenfunktionen und Eigenwerten zu den Einzelnen Elektronen Eines Atoms Physica 1104

21. Yang W and Mortier W J 1986 The use of global and local molecular parameters for the analysis of the gas-phase basicity of amines J. Am. Chem. Soc. 1085708

22. Chemouri H and Mekelleche S M 2007 Elucidation of the substituent effects on the reaction pathway of the cycloaddition of 1,3-diazabuta-1,3-dienes with ketenes using DFT-based reactivity indexes J. Mol. Struct. (THEOCHEM) $\mathbf{8 1 3} 67$

23. Aurell M J, Domingo L R, Pérez $\mathrm{P}$ and Contreras R 2004 A theoretical study on the regioselectivity of 1,3-dipolar cycloadditions using DFT-based reactivity indexes Tetrahedron 6011503

24. Houk K N 1973 Generalized frontier orbitals of alkenes and dienes. Regioselectivity in Diels-Alder reactions $J$. Am. Chem. Soc. 954092

25. Carpenter J E and Weinhold F 1988 Analysis of the geometry of the hydroxymethyl radical by the "different hybrids for different spins" natural bond orbital procedure J. Mol. Struct. (THEOCHEM) 16941 